\title{
Family history of gastric cancer correlates with decreased expression of HINT1 tumor suppressor gene in gastric mucosa of dyspeptic patients
}

\author{
KAROLINA ZUK ${ }^{1}$, LUKASZ PECZEK ${ }^{1}$, KRYSTYNA STEC-MICHALSKA ${ }^{2}$, \\ MARTA MEDREK $^{2}$ and BARBARA NAWROT ${ }^{1}$
}

${ }^{1}$ Centre of Molecular and Macromolecular Studies, Polish Academy of Sciences, Department of Bioorganic Chemistry;

${ }^{2}$ Department of Gastroenterology, Medical University of Lodz, Lodz, Poland

Received June 2, 2011; Accepted October 4, 2011

DOI: $10.3892 / \mathrm{ol} .2011 .456$

\begin{abstract}
Gastric cancer (GC) is the fourth most common cancer and the second most common cause of cancer-associated mortality worldwide. Approximately $10 \%$ of gastric cancers are hereditary and a small percentage of these cases (1-3\%) have been classified as a single hereditary syndrome (hereditary diffuse gastric cancer). We previously demonstrated that a family history of gastric cancer (FHGC) contributes to a predisposition towards the development of gastric cancer. Our data revealed that for dyspeptic patients whose first-degree relative(s) succumbed to GC, the levels of the fragile histidine triad pro-apoptotic protein in gastric mucosa were decreased. Another member of the histidine triad protein superfamily is histidine triad nucleotide-binding protein 1 (HINT1), a novel tumor suppressor that plays an inhibitory role in the control of gene transcription. The study comprised 38 ethnically homogeneous patients with dyspeptic symptoms without concomitant chronic diseases (18 controls/20 patients with FHGC). The results showed that the samples from the control patients predominantly exhibited non-atrophic changes (approximately 90\%), whereas atrophic changes occurred more frequently in patients with FHGC. Notably, the expression levels of the HINT1 gene were markedly higher in the samples with atrophy taken from the antrum of FHGC patients compared to the non-atrophic samples. Moreover, the levels of HINT1 mRNA in samples obtained from the antrum of patients with FHGC were lower compared to analogous samples from the control individuals. The decreased levels of HINT1 mRNA in the antrum samples of patients with the FHGC indicate that it is a factor predisposing those patients to the development of gastric cancer.
\end{abstract}

Correspondence to: Dr Lukasz Peczek, Centre of Molecular and Macromolecular Studies, Polish Academy of Sciences, Department of Bioorganic Chemistry, Sienkiewicza 112, Lodz 90-363, Poland E-mail: 1peczek@bio.cbmm.lodz.pl

Key words: family history, gastric cancer, HINT1, hereditary factor, tumor suppressor gene

\section{Introduction}

Gastric cancer (GC) is the fourth most common cancer and the second most common cause of cancer-associated death worldwide. Approximately $10 \%$ of gastric cancers are hereditary and a low percentage of these cases (1-3\%) has been classified as a single hereditary syndrome. Hereditary diffuse gastric cancer (HDGC) (1) is an autosomal-dominant inherited cancer syndrome in which affected individuals develop diffuse-type gastric cancer at a young age (2). Approximately $30 \%$ of families fulfilling the HDGC criteria possess a second allele of the E-cadherin gene $\mathrm{CDH} 1$ inactivated due to methylation or mutation events. $\mathrm{CDH} 1$ inactivation is currently the only genetic disorder described as predisposing to the hereditary type of gastric cancers $(3,4)$.

Although the etiopathogenesis of GC is not fully understood, it is evident that genetic factors increase the risk of disease. In a previous study, we demonstrated that a family history of gastric cancer (FHGC) predisposes patients towards the development of gastric cancer $(6,7)$. Our data revealed that, for dyspeptic patients whose first degree relative(s) died of $\mathrm{GC}$, the expression of the fragile histidine triad (FHIT) gene, a tumor suppressor gene (5), in gastric mucosa was inhibited $(6,7)$. A reduced expression of the FHIT gene has been observed in the majority of gastric cancers and a number of other organ tumors $(8,9)$. The FHIT protein is a member of the evolutionarily highly conserved HIT protein superfamily. Another HIT protein is the histidine triad nucleotide binding protein 1 (HINT1), a novel tumor suppressor that plays an inhibitory role in controlling gene transcription. It was previously revealed that the involvement of HINT1 in the regulation of a number of apoptotic pathways is independent of its enzymatic activity (10). HINT1 is deficient in gastric (11) and colon cancers (12) and in mammary and ovarian tumors (13). Moreover, down-regulation of the HINT1 gene may stimulate the development of hepatocarcinoma (14). In this context, we investigated whether FHGC correlates with the expression of HINT1 tumor suppressor gene in the gastric mucosa of patients with dyspepsia. Detailed analysis of the level of HINT1 expression in the antrum and corpus of the 
Table I. Characteristics of patients enrolled in the studies and the number of collected biopsy specimens from the antrum and corpus.

\begin{tabular}{lcccc}
\hline Group & $\begin{array}{c}\text { Selection } \\
\text { criterion }\end{array}$ & $\begin{array}{c}\text { Gender } \\
(\mathrm{F} / \mathrm{M})\end{array}$ & $\begin{array}{c}\text { No. of biopsy } \\
\text { specimens (A/C) }\end{array}$ & $\begin{array}{c}\text { Age } \\
\text { mean } \pm \text { SD, } \\
\text { range (years) }\end{array}$ \\
\hline I & $\begin{array}{c}\text { No family history } \\
\text { of gastric cancer }\end{array}$ & $(6 / 12)$ & 108 & $34.1 \pm 11.2$ \\
II & $\begin{array}{c}\text { Family history } \\
\text { of gastric cancer }\end{array}$ & $(7 / 13)$ & $(54 / 54)$ & $18-53$ \\
& & 120 & $39.6 \pm 13.7$ \\
\hline
\end{tabular}

A, antrum; C, corpus; F, female; M, male.

stomach may aid in the elucidation of the molecular basis for understanding of the gastric cancer development.

\section{Materials and methods}

Patients. The study comprised 38 ethnically homogeneous patients with dyspeptic symptoms, without concomitant chronic diseases. The screened patients were divided into two groups: Group I (control) comprising 18 patients (mean age 34.1 \pm 11.2 ) without FHGC, and Group II including 20 patients (mean age 39.6 \pm 13.7 ) with FHGC. FHGC was defined as patients having at least one first degree relative who succumbed to gastric cancer prior to the age of 60 , and another family member who was diagnosed with cancer of any organ. Data on the type of GC were not collected. Smokers, patients receiving NSAIDs or PPIs 14 days prior to the study, as well as Helicobacter pylori (H. pylori)-positive patients, were not recruited to the study. Subjects underwent a gastroscopy with biopsy procedure. The study was conducted in accordance with the Declaration of Helsinki and the principles of Good Clinical Practice. These studies were approved by the Ethical Commission of the Medical University of Lodz, Poland. Each patient was acquainted with the aim of the study prior to being recruited to the research program and provided informed, written consent to participate in the study. The characteristics of the patients are shown in Table I.

Bioptates. During endoscopic biopsy, 6 bioptates were collected from each patient: 3 from the antrum and 3 from the corpus (in total, 228 biopsy specimens). Of these, 2 samples from each topographical site were used for molecular biology screenings (to determine the level of expression of the selected genes) and the remaining samples were used for histopathological assessment. The gastric mucosa specimens were removed from the antrum at $3-5 \mathrm{~cm}$ proximally from the pylorus and from the corpus at $5-8 \mathrm{~cm}$ distally from the cardia.

Histopathological assessments. Histopathological assessments were performed using hematoxylin-eosin and Giemsa staining. For a given patient, two paraffin-embedded tissue blocks (from the antrum and corpus) were used for a microscopic section preparation (76 samples). A total of 2 sections were obtained from each paraffin block. The microscopic gastric mucosa assessment was based on a scale according to the modified Sydney System classification (15).

Isolation of total RNA from biopsies. A biopsy sample was placed in a labeled sterile tube and stored for further studies at $-70^{\circ} \mathrm{C}$ for $2-4$ weeks. Defrosted material was washed three times with PBS buffer without $\mathrm{Ca}^{2+}$ and $\mathrm{Mg}^{2+}$ ions. After washing, the specimen was transferred to a manual homogenizer and $1 \mathrm{ml}$ of lysing reagent (TriPure Isolation Reagent, Mannheim, Germany) was added. Total RNA was isolated from the homogenate according to the manufacturer's instructions for TriPure Isolation Reagent. This fraction was then used for determination of the level of expression of the selected genes.

Real time RT-PCR. The level of HINT1 and GAPDH mRNAs in a biopsy specimen was determined by a real time quantitative reverse transcription polymerase chain reaction (qRT-PCR). Samples were analyzed blind to the FHGC status. The primers (listed in Table II) were designed with the Primer3 program available at: http://frodo.wi.mit. edu/cgibin/primer3/primer3_www.egi. Isolated total RNA (200 ng/2 $\mu \mathrm{l}$ ), and each primer ( $1 \mu \mathrm{l}$ of $3 \mu \mathrm{M}$ solution) was added to the enzymatic reaction $(6 \mu 1)$ containing LC RT-PCR reaction mix SYBR-Green I $(2 \mu 1)$, LC RT-PCR enzyme mix $(0.2 \mu \mathrm{l}), \mathrm{MgCl}_{2}(5 \mathrm{mM}, 0.8 \mu \mathrm{l})$ stock solution and PCR-grade water (Roche Applied Science, Mannheim, Germany). Amplification conditions were as follows: reverse transcription of the RNA template at $55^{\circ} \mathrm{C}$ for $10 \mathrm{~min}$, deactivation of the reverse transcriptase at $95^{\circ} \mathrm{C}$ for $30 \mathrm{sec}$; amplification of cDNA: denaturation $\left(95^{\circ} \mathrm{C}\right.$ for $\left.0 \mathrm{sec}\right)$, annealing $\left(56^{\circ} \mathrm{C}\right.$ for $15 \mathrm{sec})$ and extension $\left(72^{\circ} \mathrm{C}\right.$ for $\left.13 \mathrm{sec}\right)$. The products were identified by the thermal dissociation method and electrophoresis in $2 \%$ agarose gel. The melting temperatures $(\mathrm{Tm} \pm \mathrm{SD})$ for the amplification products of GAPDH and HINT1 genes were $84.86 \pm 0.27$ and $80.42 \pm 0.29^{\circ} \mathrm{C}$, respectively.

Statistical analysis. The level of HINT1 gene expression was normalized to the level of GAPDH mRNA. Data are given as a ratio of HINT1 to GAPDH products $(H I N T 1 / G A P D H)$. The Shapiro-Wilk W test was used to analyze the normality of the data distribution. The differences between two independent groups of data were calculated using the non-parametric Mann-Whitney U test. Histopathological assessment data 
Table II. Primers used for amplification of HINT1 and GAPDH genes.

\begin{tabular}{lccc}
\hline Amplified gene & $\begin{array}{c}\text { Accession } \\
\text { number }\end{array}$ & Primer sequence & $\begin{array}{c}\text { Amplicon } \\
\text { size (bp) }\end{array}$ \\
\hline HINT1 & NM_005340.5 & F: 5'-CCG CAA GGA AAT ACC AG-3' & 160 \\
& & R: 5'-GTG TCC AAG AAG ACT TTC ATC-3' & 159 \\
GAPDH & NM_002046.3 & F: 5'-CAT CAT CTC TGC CCC CTC TG-3' & \\
& & R: 5'-TCC ACG ATA CCA AAG TTG TC-3' & \\
\hline F, forward; R, reverse. & & & \\
\hline
\end{tabular}

Table III. Results of histopathological examination of 76 samples of gastric mucosa from 18 patients of Group I and 20 patients of Group II ${ }^{\text {a }}$.

\begin{tabular}{lcc}
\hline Selection criterion & \multicolumn{2}{c}{$\begin{array}{c}\text { Number of bioptates } \\
\text { from antrum/corpus }(\%)\end{array}$} \\
\cline { 2 - 3 } & Non-atrophy & Atrophy \\
\hline Group I & $16 / 18$ & $2 / 0$ \\
(without FHGC) & $(88.9 / 100.0)$ & $(11.1 / 0.0)$ \\
Group II & $12 / 16$ & $8 / 4$ \\
(with FHGC) & $(60.0 / 80.0)$ & $(40.0 / 20.0)$
\end{tabular}

${ }^{\mathrm{a}}$ Group I samples: 18 from the antrum and 18 from the corpus and Group II samples: 20 from the antrum and 20 from the corpus.

were analyzed according to the Fisher's exact test. Statistical analyses were carried out using Statistica ver. 8.0 software (StatSoft Inc., Tulsa, OK, USA). P<0.05 was considered to be statistically significant.

\section{Results}

Histopathological analysis of biopsy specimens. Histopathological microscopic examination of hematoxylin-eosinand Giemsa-stained samples from the antrum and the corpus (taken from both groups of patients) was performed according to the modified Sydney System scale. The results (Table III) show that the samples from patients without FHGC (the control group) predominantly exhibited non-atrophic changes (approximately 90\%). Atrophic changes were observed only in four biopsy specimens obtained from the antrum. None of the control patients had atrophic changes in the corpus. Results of the statistical analysis with the Fisher's exact test showed that atrophic changes occur more frequently in patients with FHGC in the antrum $(40 \%)$ and corpus $(20 \%)$ samples $(\mathrm{p}=0.0081$ and $\mathrm{p}=0.0057$, respectively).

Level of HINT1 mRNA in gastric mucosa specimens. The level of HINT1 protein mRNA in biopsy specimens (2 samples from the corpus and 2 from the antrum of each patient, total 152 samples) was determined by the real time RT-PCR analysis. $G A P D H$ was used as a reference gene. The results are expressed as a ratio of the amounts of HINT1 mRNA to GAPDH mRNA. For each sample the amplification reaction was performed in duplicate. The results were statistically analyzed in respect to histopathological changes, stomach topography and FHGC.

HINT1 mRNA level versus histopathological changes. Only non-atrophic and atrophic changes as per the Sydney System scale were considered. No statistically significant differences were observed between the mRNA levels of HINT1 of the non-atrophic and atrophic samples taken from the antrum of the control patients (Fig. 1A) and the corpus of the FHGC patients (Fig. 1C) due to the limited number of samples with atrophy. The samples from the corpus of Group I patients were not analyzed due to the lack of atrophic changes. Notably, the level of expression of HINT1 gene was substantially higher in the atrophic samples taken from the antrum of patients of Group II (with FHGC) compared to the non-atrophic samples (Fig. 1B) $(\mathrm{p}=0.001040)$. The samples with atrophic changes were excluded from further analysis due to the statistically significant increase of their HINT1 mRNA levels.

HINT1 mRNA level versus stomach topography. Analysis of the samples with non-atrophic changes (from both groups of patients) in respect to their site of origin (antrum versus corpus) revealed that the level of HINT1 protein mRNA was independent of the stomach topography (Fig. 2A and B, respectively).

HINT1 mRNA level versus family history of gastric cancer. Analysis of the samples from the antrum revealed that the level of HINT1 mRNA was lower for patients with FHGC compared to the control $(\mathrm{p}=0.003959)$ (Fig. 3A). Conversely, in samples from the corpus the difference between levels of HINT1 mRNA between the two groups was statistically non-significant ( $\mathrm{p}=0.472116$ ) (Fig. 3B).

\section{Discussion}

The HINT1 protein plays an inhibitory role in a number of gene transcription control pathways. This protein inhibits the activity of cyclin-dependent kinase 7, microphthalmia-associated transcription factor, the transcription factor USF2, the Pontin/ Reptin/ $\beta$-catenin/TCF4 complex and the AP-1 transcription factor (16-18).

In their study, Wang et al proposed that, the HINT1 protein acts as a tumor suppressor due to the inhibitory activity towards transcription factors (12). It has been demonstrated that after 
A

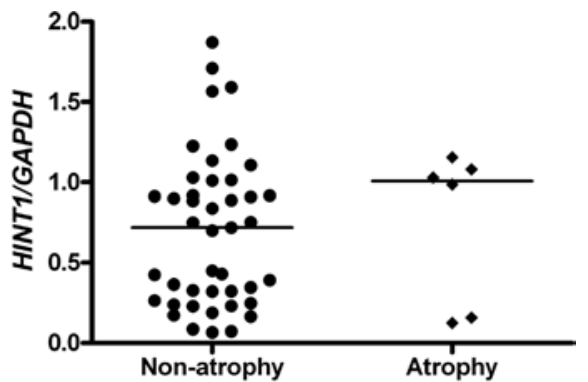

B

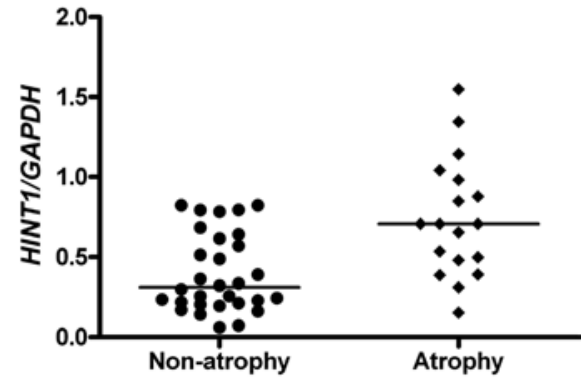

C

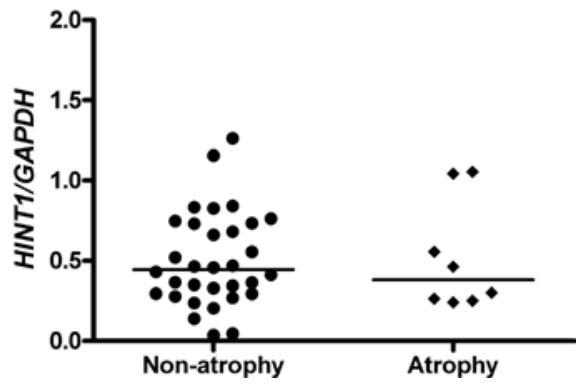

Figure 1. The levels of mRNA of the HINT1 protein (normalized to the level of mRNA of the reference GAPDH) in a series of biopsy specimens (with non-atrophic or atrophic changes) obtained from: (A) the antrum, Group I, $\mathrm{p}=0.625553$, (B) the antrum, Group II, $\mathrm{p}=0.001040$, and (C) the corpus, Group II, $\mathrm{p}=0.839232$. The medians are marked as horizontal lines.

association to complex of the plenty of SH3 domains protein (POSH) and c-Jun NH(2)-terminal kinase (POSH-JNK2), HINT1 inhibits activity of the AP-1 transcription factor responsible for proliferation and angiogenesis of colon cancer cells. A lower expression of HINT1 has been observed in colon, breast, lung and liver cancers (12). In our study, the level of HINT1 mRNA is statistically higher in gastric mucosa with atrophic changes in comparison with non-atrophic changes, and only in samples from the antrum, independently of FHGC (Fig. 1B). In the context of the widely accepted hypothesis that atrophic changes described by the Correa cascade are critical in gastric carcinogenesis, this observation indicates that elevated levels of HINT1 are a response from gastric mucosa cells in defense against the development of distal gastric cancer. Another study has examined the pro-apoptotic function of HINT1 (10). Decreased HINT1 levels are observed in breast and colon cancers, in which expression of the pro-apoptotic Bax protein is up-regulated and that of anti-apoptotic Bcl-2 protein is down-regulated, whereas silencing of HINT1 results in decreased biosynthesis of Bax and $\mathrm{p} 53$ proteins. An increased expression of HINT1 in human hepatoma cells, achieved by
A

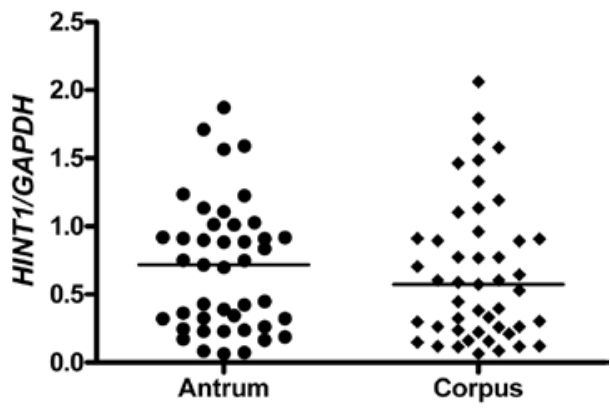

B

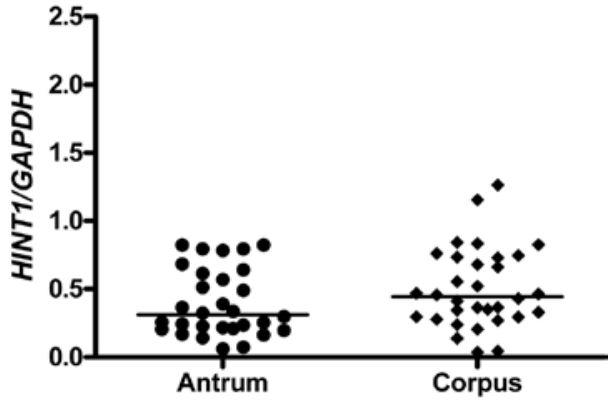

Figure 2. The level of mRNA of HINT1 protein (normalized to the level of mRNA of the reference GAPDH) in respect to the stomach topography (antrum versus corpus), in the non-atrophic biopsy specimens. (A) Group I $\mathrm{p}=0.474687$, (B) Group II $\mathrm{p}=0.102267$. The medians are marked as horizontal lines.

A

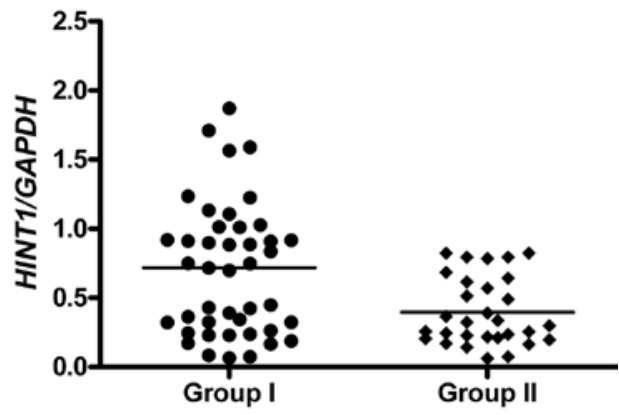

B

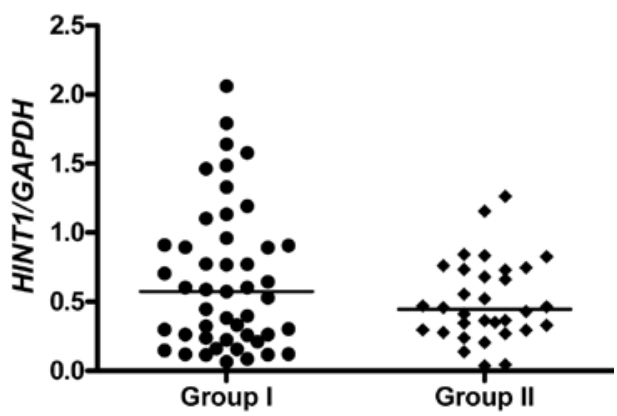

Figure 3. The levels of expression of the HINT1 gene in samples from the (A) antrum and (B) corpus of patients from Groups I and II. The level of HINT1 mRNA was normalized to the level of mRNA of the reference GAPDH. The medians are marked as horizontal lines.

inhibition of DNA methylation, has been shown to markedly inhibit their growth (14). Treatment of HINT1-/- mice with NBCA (N-nitrosomethylbenzylamine), a known carcinogenic 
agent, induced four adenomas and one adenocarcinoma of the glandular stomach. This effect was not observed in HINT1+/+ mice (11).

Our analysis of the levels of HINT1 mRNA in the corpus and antrum samples of patients with FHGC and the control patients indicated a lack of dependence of HINT1 expression on stomach topography (Fig. 2). On the other hand, the level of HINT1 expression depends on the FHGC, and the differences between the control and FHGC individuals reached statistical significance for samples from the antrum, but not from the corpus (Fig. 3). In this case, the lowered level of HINT1 indicates increased susceptibility to GC.

Since HINT1 expression is lowered in GC tissues, etiological factors such as $H$. pylori infection or promoter hypermethylation may play a role in gastric tumorigenesis by regulation of the HINT1 gene expression (20). Increased spontaneous tumor formation has been observed in mice bearing a deletion of the HINT gene (11). Moreover, it has been proposed that defects caused by the loss of HINT1 may occur only when FHIT protein (another member of the HIT family, which may recognize HINT1 substrates in vivo) is also inactivated (21). In earlier studies, we demonstrated that genetic and environmental factors, including FHGC, affect the level of expression of FHIT tumor suppressor $(6,7)$. In gastric mucosa of patients with FHGC the FHIT gene expression was down-regulated in comparison to the controls. Moreover, an increased level of FHIT gene promoter methylation was associated with hereditary (FHGC) and environmental factors (infection with $H$. pylori) and resulted in the down-regulation of the FHIT gene transcription (22). Therefore, a lowered level of expression of HINT1, especially in the stomach antrum, may predispose towards the development of GC. Further studies are in progress to determine the clinical relevance of HINT1 expression in the prevention of prepyloric gastric carcinoma in patients with a family history of gastric cancer.

\section{Acknowledgements}

These studies were supported by the Ministry of Science and Higher Education, Poland, during the period 2009-2012 (project N N402 307336 for B.N.).

\section{References}

1. Oliveira C, Seruca R and Carneiro F: Hereditary gastric cancer. Best Pract Res Clin Gastroenterol 23: 147-157, 2009.

2. Cisco RM, Ford JM and Norton JA: Hereditary diffuse gastric cancer: implications of genetic testing for screening and prophylactic surgery. Cancer 113: 1850-1856, 2008.

3. Fitzgerald RC, Hardwick R, Huntsman D, Carneiro F, Guilford P, Blair V, Chung DC, Norton J, Ragunath K, Van Krieken JH, et al: Hereditary diffuse gastric cancer: updated consensus guidelines for clinical management and directions for future research. International Gastric Cancer Linkage Consortium. J Med Genet 47: 436-444, 2010.
4. Oliveira C, Bordin MC and Grehan N, Huntsman D, Suriano G, Machado JC, Kiviluoto T, Aaltonen L, Jackson CE and Caldas C: Screening E-cadherin in gastric cancer families reveals germline mutations only in hereditary diffuse gastric cancer kindred. Hum Mutat 19: 510-517, 2002.

5. Ishii $\mathrm{H}$, Ozawa $\mathrm{K}$ and Furukawa $\mathrm{Y}$ : Alteration of the fragile histidine triad gene early in carcinogenesis: an update. J Exp Ther Oncol 3: 291-296, 2003

6. Stec-Michalska K, Antoszczyk S, Klupinska G and Nawrot B: Loss of FHIT expression in the gastric mucosa of patients with family history of gastric cancer and Helicobacter pylori infection. World J Gastroenterol 11: 17-21, 2005.

7. Stec-Michalska K, Peczek L, Michalski B, WisniewskaJarosinska M, Krakowiak A and Nawrot B: Helicobacter pylori infection and family history of gastric cancer decrease expression of FHIT tumor suppressor gene in gastric mucosa of dyspeptic patients. Helicobacter 14: 126-134, 2009.

8. Baffa R, Veronese ML, Santoro R, Mandes B, Palazzo JP, Rugge M, Santoro E, Croce CM and Huebner K: Loss of FHIT expression in gastric carcinoma. Cancer Res 58: 4708-4714, 1998.

9. Lee SH, Kim WH, Kim HK, Woo KM, Nam HS, Kim HS, Kim JG and Cho MH: Altered expression of the fragile histidine triad gene in primary gastric adenocarcinomas. Biochem Biophys Res Commun 284: 850-855, 2001.

10. Weiske $\mathrm{J}$ and Huber O: The histidine triad protein HINT1 triggers apoptosis independent of its enzymatic activity. J Biol Chem 281: 27356-27366, 2006.

11. Su T, Suzui M, Wang L, Lin CS, Xing WQ and Weinstein IB: Deletion of histidine triad nucleotide-binding protein 1/PKCinteracting protein in mice enhances cell growth and carcinogenesis. Proc Natl Acad Sci USA 100: 7824-7829, 2003.

12. Wang L, Zhang Y, Li H, Xu Z, Santella RM and Weinstein IB: HINT1 inhibits growth and activator protein-1 activity in human colon cancer cells. Cancer Res 67: 4700-4708, 2007.

13. Li H, Zhang Y, Su T, Santella RM and Weinstein IB: HINT1 is a haplo-insufficient tumor suppressor in mice. Oncogene 25: 713-721, 2006.

14. Zhang YJ, Li H, Wu HC, Shen J, Wang L, Yu MW, Lee PH, Weinstein IB and Santella RM: Silencing of HINT1, a novel tumor suppressor gene, by promoter hypermethylation in hepatocellular carcinoma. Cancer Lett 275: 277-284, 2009.

15. Dixon MF, Genta RM, Yardley JH and Correa P: Classification and grading of gastritis. The updated Sydney System. International Workshop on the Histopathology of Gastritis, Houston 1994. Am J Surg Pathol 20: 1161-1181, 1996.

16. Korsisaari N and Makela TP: Interactions of Cdk7 and Kin28 with Hint/PKCI-1 and Hnt1 histidine triad proteins. J Biol Chem 275: 34837-34840, 2000.

17. Weiske $J$ and Huber O: The histidine triad protein HINT1 interacts with Pontin and Reptin and inhibits TCF-beta-cateninmediated transcription. J Cell Sci 118: 3117-3129, 2005.

18. Wang L, Li H, Zhang Y, Santella RM and Weinstein IB: HINT1 inhibits beta-catenin/TCF4, USF2 and NFkappaB activity in human hepatoma cells. Int J Cancer 124: 1526-1534, 2009.

19. Huang H, Wei X, Su X, Qiao F, Xu Z, Gu D, Fan H and Chen J: Clinical significance of expression of Hintl and potential epigenetic mechanism in gastric cancer. Int $\mathbf{J}$ Oncol 38: 1557-1564, 2011.

20. Guranowski A, Wojdyła AM, Pietrowska-Borek M, Bieganowski P, Khurs EN, Cliff MJ, Blackburn GM, Błaziak D and Stec WJ: Fhit proteins can also recognize substrates other than dinucleoside polyphosphates. FEBS Lett 582: 3152-3158, 2008.

21. Stec-Michalska K: Clinical aspects of changes of the level of expression of selected proapoptotic genes in the gastric mucosa of patients with family history of gastric cancer (habilitation dissertation). Medical University of Lodz, Poland, 2010. 